\title{
Synthesis and Characterization of Molecular Imprinting Polymer Microspheres of Piperine: Extraction of Piperine from Spiked Urine
}

\author{
Rachel Marcella Roland and Showkat Ahmad Bhawani \\ Department of Chemistry, Faculty of Resource Science and Technology, Universiti Malaysia Sarawak (UNIMAS), \\ 94300 Kota Samarahan, Sarawak, Malaysia \\ Correspondence should be addressed to Showkat Ahmad Bhawani; sabhawani@gmail.com
}

Received 6 September 2016; Accepted 18 October 2016

Academic Editor: Núria Fontanals

Copyright (C) 2016 R. M. Roland and S. A. Bhawani. This is an open access article distributed under the Creative Commons Attribution License, which permits unrestricted use, distribution, and reproduction in any medium, provided the original work is properly cited.

\begin{abstract}
Molecularly imprinted polymer (MIP) microspheres for Piperine were synthesized by precipitation polymerization with a noncovalent approach. In this research Piperine was used as a template, acrylic acid as a functional monomer, ethylene glycol dimethacrylate as a cross-linker, and 2,2' -azobisisobutyronitrile (AIBN) as an initiator and acetonitrile as a solvent. The imprinted and nonimprinted polymer particles were characterized by using Fourier transform infrared spectroscopy (FT-IR) and Scanning Electron Microscopy (SEM). The synthesized polymer particles were further evaluated for their rebinding efficiency by batch binding assay. The highly selected imprinted polymer for Piperine was MIP 3 with a composition (molar ratio) of $0.5: 3: 8$, template:monomer:cross-linker, respectively. The MIP 3 exhibits highest binding capacity (84.94\%) as compared to other imprinted and nonimprinted polymers. The extraction efficiency of highly selected imprinted polymer of Piperine from spiked urine was above $80 \%$.
\end{abstract}

\section{Introduction}

Piperine, a nitrogenous pungent substance, is an alkaloid found in important and oldest spices, namely, Piper nigrum (black peppers) and Piper longum (long peppers) [1]. It is also known as 1-piperoylpiperidine with the chemical formula of $\mathrm{C}_{17} \mathrm{H}_{19} \mathrm{NO}_{3}$. Hamrapurkar et al. [2] stated that Piperine is naturally occurring organic compound that belongs to family Piperaceae. The fruits of Piperine possess antidepressant effects, hepatoprotective effects, antioxidant activity, antitumour effects, antibacterial effects, and anticonvulsant effects $[2,3]$. Piperine also has the capability of reducing inflammation, relieving pain, improving digestion, and enhancing the bioavailability [4]. Piperine is extensively used in medicinal field for years due to various medicinal properties including painkiller, antioxidant, and bioavailability enhancer.

Molecular Imprinting Technology (MIT) is used to design molecular recognition materials because it is capable of mimicking natural recognition entities like antibodies and biological receptors [5-14]. The original concept of molecular imprinting is developed by Linus Pauling in 1940s, but Wulff and Sarhan stimulated the interest in imprinting materials [6]. According to Vlatakis et al. [15], in the early 1980s, the molecular imprinting polymers (MIPs) were successfully prepared by using noncovalent MIT.

Molecular imprinting is a universal method to produce polymers with high affinity binding sites for organic, inorganic, biological, and chemical molecules or ions. MIPs allow the functional and crosslinking monomers to copolymerize in the presence of the target compound or known as template [16]. Molecular imprinting polymers [17] can be prepared by various methods such as bulk polymerization [18], electropolymerization [19], suspension polymerization [20], emulsion polymerization, two-step polymerization [21], and precipitation polymerization [22]. Zhou et al. [23] mentioned that the controlled/living radical polymerization (CRP) is used to prepare MIP microspheres as it permits more precise control over the molecular weight, composition, and end 
group functionality of the obtained polymers [24-27]. MIPs show excellent thermal and chemical stability and can be used in aggressive media [15]. According to Yan and Row [28], MIPs have many advantages over their biological counterparts including inexpensive, simple preparation, storage stability, repeated operations without loss of activity, high mechanical strength, durability to heat and pressure, and applicability in harsh chemical media.

Lai et al. [29] stated that MIPs have been used in important application such as chemical sensors [30, 31], capillary electrophoresis and electrochromatography [32], catalysis [33], HPLC stationary phases [34-39], and solidphase extraction (SPE) [36].

In this research noncovalent imprinting or self-assembly approach is adopted during the course of polymerization. In noncovalent imprinting, the template and a functional monomer interact by noncovalent interactions in the prepolymerization mixture. According to Spivak [40], noncovalent is simpler molecular imprinting method as compared to covalent and semicovalent because it involves synthetic steps toward the prepolymer complex. In this way interaction between the monomer and template is achieved easily when mixed in the solution. This method has been used to produce imprinted polymers of cinnamic acid. In this research as an application these imprinted polymers are used in extraction of Piperine from spiked urine sample.

\section{Materials and Methods}

2.1. Materials. Piperine $\left(\mathrm{C}_{17} \mathrm{H}_{19} \mathrm{NO}_{3}\right)$ was purchased from Sigma-Aldrich Co. Ltd. (United States), acrylic acid (AA) was bought from Nippon Shokubai Co. Ltd. (Japan), ethylene glycol dimethacrylate (EGDMA) was purchased from SigmaAldrich Co. Ltd. (United States), acetonitrile (ACN) was obtained from Kunshan Yalong Trading Co. Ltd. (China), 2, $2^{\prime}$-azobisisobutyronitrile (AIBN) was obtained from SigmaAldrich Co. Ltd. (United States), methanol (MeOH) was obtained from Nuasa Kimia Sejati Co. (Indonesia), acetic acid $\left(\mathrm{CH}_{3} \mathrm{COOH}\right)$ was purchased from Alpha Chemika (India), potassium bromide $(\mathrm{KBr})$ was obtained from Powder Pack Chem Co. (India), and hexane was obtained from Seidler Chemical Co. (United States).

2.2. Equipment. Branson 2510 ultrasonic cleaner was used to disperse the mixtures. Memmert W350T Water BathAAR 3060 was used to carry out the polymerization. IR spectra of polymer particles were recorded with Thermo Scientific Nicolet iS10. Scanning electron microscope (JEOL JSM-6390LA) was used to study the morphology of polymer particles. Shaker (NB-101MT) was used to allow the rebinding of polymer particles with template. EBA 20-Hettich was used to centrifuge and separate the polymer particles from the solution. Shimadzu LC-20A, a reversed-phase high performance liquid chromatography (RP-HPLC), was used to evaluate the batch binding of polymer particles.

2.3. Synthesis of MIPs and NIP of Piperine. The following procedure was followed during the preparation. $0.5 \mathrm{mmol}$ of template (Piperine), $2 \mathrm{mmol}$ of monomer (AA), $8 \mathrm{mmol}$ of cross-linker (EGDMA), $75 \mathrm{~mL}$ of porogen (ACN), and $0.011 \mathrm{~g}$ of initiator (AIBN) were added into $150 \mathrm{~mL}$ conical flask, respectively. The mixture was sonicated for 10 minutes in order to remove bubbles and allow complete dissolution. Then, the conical flask containing mixture was placed in a bucket of ice cubes and the reaction mixture was purged with nitrogen gas for 15 minutes. Ice cubes were used in this experiment to allow a suitable environment for noncovalent interactions between Piperine and acrylic acid. After that, the conical flask was sealed and placed into a water bath. The polymerization was conducted for 6 hours, initially temperature was maintained at $60^{\circ} \mathrm{C}$ for the first three hours, and later temperature was raised up to $80^{\circ} \mathrm{C}$ and maintained for another three hours in order to complete the polymerization. The produced polymer particles were extracted out by using the centrifugation at $5000 \mathrm{rpm}$ for $10 \mathrm{~min}$. The template was removed by washing the MIPs successively in the mixture of methanol and acetic acid $(9: 1, \mathrm{v} / \mathrm{v})$ until the template was not detected by RP-HPLC at $270 \mathrm{~nm}$. The HPLC was conducted by using the C18 column $(250 \times 4 \mathrm{~mm}, 5 \mu \mathrm{m})$ with the mobile phase consisting of acetonitrile, distilled water, and acetic acid in the ratio of $60: 39.5: 0.5, \mathrm{v} / \mathrm{v} / \mathrm{v}$, respectively. The flow rate was set at $0.6 \mathrm{~mL} / \mathrm{min}$ with $\mathrm{UV}$ detection at $270 \mathrm{~nm}$ and injection volume was set at $20 \mu \mathrm{L}$.

The nonimprinted polymeric particles (NIPs) were prepared in the same way without the addition of the template molecule. The similar procedure was used for the synthesis of different molecular imprinted polymers of Piperine with varying composition of AA and EGDMA (Table 1) by precipitation polymerization, namely, MIP 2, MIP 3, and MIP 4 for MIPs as well as NIP.

2.4. Batch Binding Assay. A series of $150 \mathrm{~mL}$ five conical flasks containing $0.5 \mathrm{~g}$ of the MIP (MIP 1, MIP 2, MIP 3, and MIP 4) and NIP beads were added with a $75 \mathrm{~mL}$ of acetonitrile containing $0.5 \mathrm{mmol}$ of Piperine. The conical flasks were shaken on the shaker at $100 \mathrm{rpm}$ and the samples were collected at different time intervals $(0,30,60,90,120,150,240$, and 360 minutes). The collected samples were centrifuged at $5000 \mathrm{rpm}$ for 10 minutes in order to remove any suspended particles and supernatant was used for further analysis. The concentrations of Piperine after adsorption were recorded by using RP-HPLC. The binding capacity of MIPs and NIP of Piperine was calculated [17] by using the following equation:

$$
\text { Binding capacity }(\%)=\frac{C_{i}-C_{f}}{C_{i}} \times 100,
$$

where $C_{i}$ is the initial Piperine concentration in the solution and $C_{f}$ is the final Piperine concentration in the solution.

2.5. Competitive Binding Test. Caffeine was used as a competitive template with the Piperine. A $150 \mathrm{~mL}$ conical flask containing $0.5 \mathrm{~g}$ of the MIP 3 beads was added and a solution of $75 \mathrm{~mL}$ of acetonitrile containing equal concentration $(0.5 \mathrm{mmol})$ of Piperine and Caffeine. Similarly, for NIP same procedure was followed. Both of the conical flasks were shaken on the shaker at $100 \mathrm{rpm}$ and the samples were 
TABLE 1: Synthesis of molecularly imprinted polymers and nonimprinted polymer for Piperine by precipitation polymerization.

\begin{tabular}{|c|c|c|c|c|c|}
\hline Code & MIP 1 & MIP 2 & MIP 3 & MIP 4 & NIP \\
\hline Template (mmol) & $\begin{array}{c}\text { Piperine } \\
(0.5)\end{array}$ & $\begin{array}{l}\text { Piperine } \\
(0.5)\end{array}$ & $\begin{array}{l}\text { Piperine } \\
(0.5)\end{array}$ & $\begin{array}{c}\text { Piperine } \\
(0.5)\end{array}$ & - \\
\hline Monomer (mmol) & $\begin{array}{l}\text { AA } \\
(2)\end{array}$ & $\begin{array}{l}\mathrm{AA} \\
(2)\end{array}$ & $\begin{array}{l}\mathrm{AA} \\
(3)\end{array}$ & $\begin{array}{l}\mathrm{AA} \\
(3)\end{array}$ & $\begin{array}{l}\text { AA } \\
(3)\end{array}$ \\
\hline Cross-linker (mmol) & $\begin{array}{l}\text { EGDMA } \\
(8)\end{array}$ & $\begin{array}{c}\text { EGDMA } \\
(12)\end{array}$ & $\begin{array}{c}\text { EGDMA } \\
(8)\end{array}$ & $\begin{array}{c}\text { EGDMA } \\
(12)\end{array}$ & $\begin{array}{c}\text { EGDMA } \\
(8)\end{array}$ \\
\hline Porogen (mL) & $\begin{array}{c}\mathrm{ACN} \\
(75)\end{array}$ & $\begin{array}{c}\mathrm{ACN} \\
(75)\end{array}$ & $\begin{array}{c}\mathrm{ACN} \\
(75)\end{array}$ & $\begin{array}{c}\mathrm{ACN} \\
(75)\end{array}$ & $\begin{array}{c}\mathrm{ACN} \\
(75)\end{array}$ \\
\hline
\end{tabular}

collected at different time intervals $(0,30,60,90,120,150$, 240 , and 360 minutes). After shaking at the appropriate time intervals, all the samples were centrifuged at $5000 \mathrm{rpm}$ for 10 minutes. The binding of both the templates was monitored by using RP-HPLC. The distribution ratios $\left(\mathrm{mL} \mathrm{g}^{-1}\right)$ of Piperine between the MIPs or NIP in the porogen (acetonitrile) were determined [41] by the following equation:

$$
\text { Distribution ratio: } K_{D}=\frac{\left(C_{i}-C_{f}\right) V}{C_{i} m},
$$

where $C_{i}$ is the initial Piperine concentration in the solution, $C_{f}$ is the final Piperine concentration in the solution, $V$ is the volume of porogen (ACN) used, and $m$ is the mass of MIP/NIP used.

The selectivity coefficients for Piperine relative to binding competitor Caffeine for MIP 3 and NIP can be calculated [41] by

$$
\text { Selectivity coefficient: } K_{\text {Piperine/Caffeine }}^{\text {sel }}=\frac{K_{D}^{\text {Piperine }}}{K_{D}^{\text {Caffeine }}} \text {, }
$$

where $K_{D}^{\text {Piperine }}$ is the batch binding assay of MIP/NIP for Piperine and $K_{D}^{\text {Caffeine }}$ is the batch binding assay of MIP/NIP for Caffeine.

The relative selectivity coefficient $\left(k^{\prime}\right)$ was determined [41] by the following equation:

$$
k^{\prime}=\frac{k(\mathrm{MIP} 3)}{k(\mathrm{NIP})} \text {. }
$$

2.6. Extraction of Piperine from Spiked Human Urine. About $100 \mathrm{~mL}$ of fresh urine was collected from a drug free human. Urine sample was first centrifuged and filtered and then spiked with a Piperine to get a concentration of $50 \mathrm{ppm}$. After this $50 \mathrm{~mL}$ of spiked urine sample was added in flask containing $0.5 \mathrm{~g}$ of MIP 3. The samples were collected and analysed the same as followed in batch bind assay. The NIP was treated in the same way.

\section{Results and Discussion}

Synthesis of microsphere imprinted polymers is a very crucial step in order to produce uniform shape and size of particles. Previous studies revealed [42] that various preparation methods have been carried out for the preparation of polymer microspheres [43] such as the synthesis of polymer microspheres by dispersion and emulsion polymerization, where the surfactants in aqueous solution [44] and stabilizers in organic solution [45] are crucial to stabilize the polymer phase and prevent the aggregation of particles. Precipitation polymerization can form polymer microspheres with constant size and shape that can lead to narrow dispersion, without the need for any added surfactant or stabilizer [46-49]. In this research we have successfully produced imprinted polymer microspheres by precipitation method in the acetonitrile (porogen).

3.1. Fourier Transform Infrared Spectroscopy (FT-IR). IR analysis is an important chemical characterization method to detect the functional groups present in a compound. The FTIR spectra of different MIPs and NIP are shown in Figure 1.

Based on Figure 1, small peak in the range of $3519.29 \mathrm{~cm}^{-1}$ to $3613.06 \mathrm{~cm}^{-1}$ attributed to the vibration mode of $\mathrm{O}-\mathrm{H}$ stretching was observed in both MIPs and NIP. The bands in the range of $2926.75 \mathrm{~cm}^{-1}$ to $2996.02 \mathrm{~cm}^{-1}$ and $2854.76 \mathrm{~cm}^{-1}$ to $2957.24 \mathrm{~cm}^{-1}$ showed the vibration mode of C-H stretching of aliphatic compound as well as asymmetric and symmetric $\mathrm{CH}_{2}$ stretching in MIPs and NIP. Strong peaks at $1726.11 \mathrm{~cm}^{-1}$ to $1736.42 \mathrm{~cm}^{-1}$ indicated the presence of $\mathrm{C}=\mathrm{O}$ of acrylic acid. The vibration mode of $\mathrm{C}=\mathrm{C}$ stretching of aromatic compound can be found within $1635.37 \mathrm{~cm}^{-1}$ to $1636.84 \mathrm{~cm}^{-1}$. The $\mathrm{CH}_{2}$ bending at $1450.82 \mathrm{~cm}^{-1}$ to $1452.70 \mathrm{~cm}^{-1}$ indicated the presence of alkane group in MIPs and NIP.

The vibration mode of C-N stretching of MIPs and NIPs after leaching was detected at $1388.44 \mathrm{~cm}^{-1}$ to $1390.06 \mathrm{~cm}^{-1}$. Peaks of MIPs and NIP at $1253.88 \mathrm{~cm}^{-1}$ to $1259.61 \mathrm{~cm}^{-1}$ showed the vibration mode of $-\mathrm{O}-\mathrm{CH}_{2}-\mathrm{O}-$ symmetric stretching. Small band at $1035.88 \mathrm{~cm}^{-1}$ to $1050.59 \mathrm{~cm}^{-1}$ in MIPs and NIP explained the presence of symmetric stretching of $=\mathrm{C}-\mathrm{O}-\mathrm{C}$. The vibration mode of $\mathrm{C}-\mathrm{H}$ stretching of aliphatic compound can be observed at $2954.09 \mathrm{~cm}^{-1}$ to $2985.19 \mathrm{~cm}^{-1}$.

3.2. Scanning Electron Microscopy (SEM). SEM analysis is a very important morphological study for polymer particles that provides the idea about the shape and size. Figure 2 clearly indicates that spherical particles are produced with the size in micrometres. This is because the polymer particles were synthesized by precipitation polymerization. According 


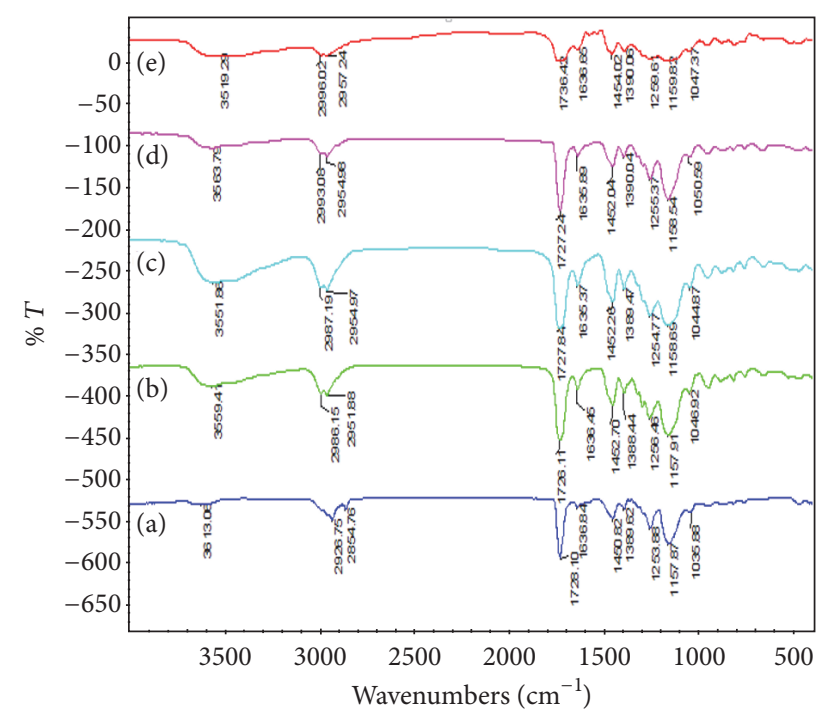

FIgUre 1: FT-IR spectra, (a) MIP 1, (b) MIP 2, (c) MIP 3, (d) MIP 4, and (e) NIP.

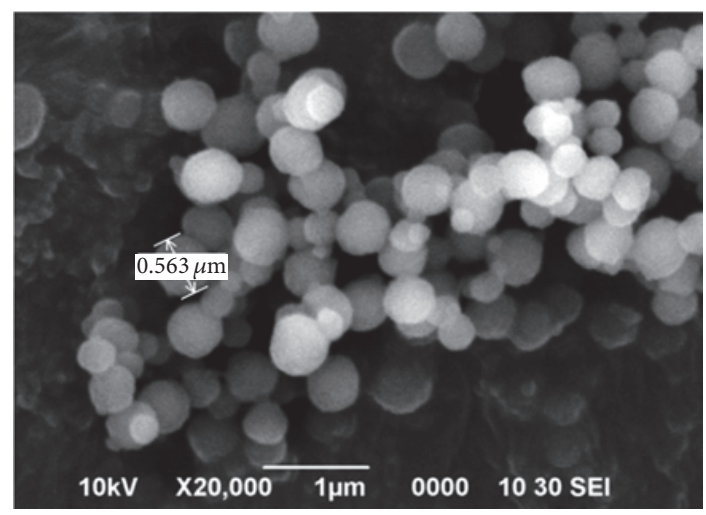

FIGURE 2: SEM of imprinted polymer particles.

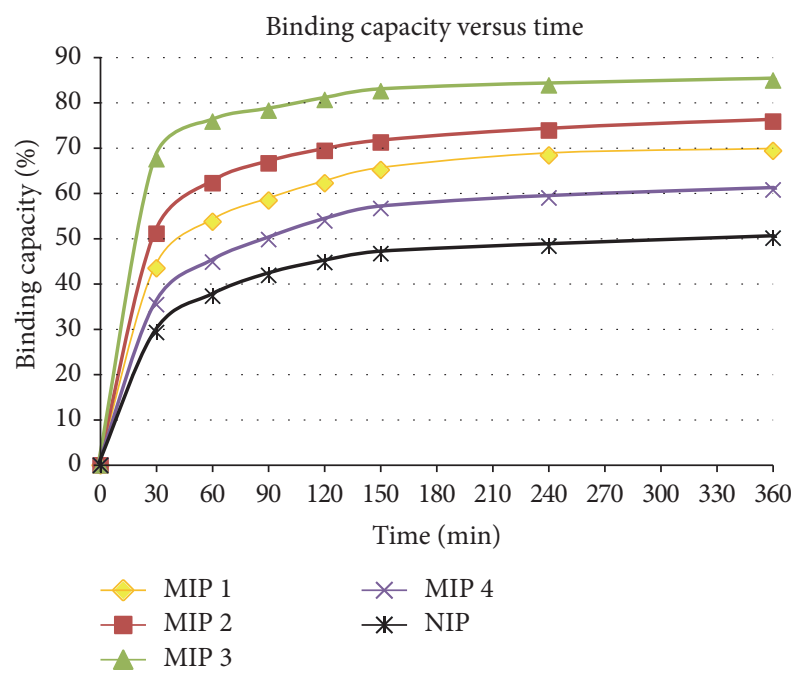

FIGURE 3: A graph of binding capacity of MIPs 1, 2, 3, and 4 and NIP at different time intervals.
TABLE 2: The distribution ratio, selectivity coefficients, and relative selectivity coefficient of MIP 3 and NIP.

\begin{tabular}{lcccc}
\hline & $\begin{array}{c}K_{D}\left(\mathrm{MIP}^{-1}\right) \\
\left(\mathrm{mL} \mathrm{g}^{-1}\right)\end{array}$ & $\begin{array}{c}K_{D}(\mathrm{NIP}) \\
\left(\mathrm{mL} \mathrm{g}^{-1}\right)\end{array}$ & $k^{\text {sel }}$ & $k^{\prime}$ \\
\hline Piperine & 76.72 & 26.79 & 5.34 & - \\
Caffeine & 14.37 & 7.70 & 3.47 & 1.54 \\
\hline
\end{tabular}

to Tamayo et al. [50], uniform size of imprinted polymers can be formed by using a noncovalent imprinting approach by precipitation polymerization.

Arabzadeh and Abdouss [41] stated that interaction between monomer and template could be another factor that contributed to uniform size distribution with clean surfaces. Research conducted by Park et al. [51] mentioned that there are various factors that affect the production of uniform polymer microspheres including volume of solvent, reaction of solvent, and presence of template ion. Excess solvent or porogen used in the synthesis of polymer particles will produce highly uniform polymer microspheres with imprinted binding sites.

3.3. Batch Binding Assay of MIPs and NIP. RP-HPLC was used to evaluate the binding efficiency of MIPs and NIP of Piperine. Figure 3 depicts the binding capacity of different MIPs and NIP at different time intervals.

MIP 3 showed the highest binding capacity (84.94\%), followed by MIP 2 (75.86\%), MIP 1 (69.40\%), and MIP 4 (60.80\%). MIP 3 contains a higher amount of monomer ratio as compared to MIP 1 and MIP 2 but MIP 4 contains a higher amount of cross-linker. In this study increasing amount of monomer would produce specific interaction sites with the Piperine and hence rebinding efficiency was also increased. But the increase in amount of cross-linker has produced a reverse effect as can be seen in MIP 4. If we compare the MIPs with NIP it is clear from Figure 3 the binding capacity is low. This can be conferred that NIP does not contain any binding site complimentary with the Piperine.

3.4. Competitive Binding Assay. In order to evaluate the properties of MIP of Piperine as a sensing material, the selectivity test was conducted. In this test, two compounds (Piperine and Caffeine) were tested using both MIP 3 and NIP. The selectivity of Piperine and Caffeine was calculated by using RP-HPLC measurements. The distribution ratio of Piperine in both MIP 3 and NIP was higher than the distribution ratio of Caffeine in both MIP 3 and NIP, resulting in higher selectivity coefficient of Piperine than that of Caffeine in both MIP 3 and NIP (Table 2). The results indicate that the imprinted polymer has got complimentary binding sites or cavities with the Piperine as compared to Caffeine.

3.5. Extraction of Piperine from Spiked Human Urine. The extensive use of Piperine in medicine and spices has generated this idea to first use the selected MIP 3 in the extraction of Piperine from urine. This will provide us a way forward to expand the application of these imprinted polymer particles. 
From this study it was found that about $81.18 \%$ of Piperine was successfully extracted from the spiked urine sample.

\section{Conclusion}

Molecularly imprinted polymeric microspheres of Piperine were synthesized by using precipitation polymerization. The binding efficiencies of MIPs and NIP of Piperine were evaluated by batch binding assay. MIP 3 exhibited the highest binding capacity (84.94\%) as compared to NIP (40\%). These imprinted polymer particles successfully extracted $(81.18 \%)$ Piperine from spiked urine.

\section{Competing Interests}

The authors declare that they have no competing interests.

\section{Acknowledgments}

Financial support from SGS UNIMAS Grant no. F07(S168)/ $1243 / 2015(05)$ is highly appreciated.

\section{References}

[1] K. P. Umesh, S. Amrit, and K. C. Anup, "Role of piperine as an bioavailability enhancer," Journal of Recent Advances in Pharmaceutical Research, vol. 4, pp. 16-23, 2011.

[2] P. D. Hamrapurkar, K. Jadhav, and S. Zine, "Quantitative estimation of piperine in Piper nigrum and Piper longum using high performance thin layer chromatography," Journal of Applied Pharmaceutical Science, vol. 1, no. 3, pp. 117-120, 2011.

[3] A. Khajuria, N. Thusa, U. Zusthi, and K. L. Bedi, "Estimation of piperine in commercial Ayurvedic formulations," Indian Drugs, vol. 34, no. 10, pp. 557-563, 1997.

[4] A. M. Mujumdar, J. N. Dhuley, V. K. Deshmukh, and S. R. Naik, "Effect of piperine on bioavailability of oxyphenylbutazone in rats," Indian Drugs, vol. 36, no. 2, pp. 123-126, 1999.

[5] T. Takagishi and I. M. Klotz, "Macromolecule-small molecule interactions; introduction of additional binding sites in polyethyleneimine by disulfide cross-linkages," BiopolymersPeptide Science Section, vol. 11, no. 2, pp. 483-491, 1972.

[6] G. Wulff and A. Sarhan, "Use of polymers with enzymeanalogous structures for the resolution of racemates," Angewandte Chemie International Edition, vol. 11, pp. 341-342, 1972.

[7] K. Mosbach and O. Ramström, "The emerging technique of molecular imprinting and its future impact on biotechnology," Nature Biotechnology, vol. 14, no. 2, pp. 163-170, 1996.

[8] M. J. Whitcombe, M. E. Rodriguez, P. Villar, and E. N. Vulfson, "A new method for the introduction of recognition site functionality into polymers prepared by molecular imprinting: synthesis and characterization of polymeric receptors for cholesterol," Journal of the American Chemical Society, vol. 117, no. 27, pp. 7105-7111, 1995.

[9] C. Alexander, H. S. Andersson, L. I. Andersson et al., "Molecular imprinting science and technology: a survey of the literature for the years up to and including 2003," Journal of Molecular Recognition, vol. 19, no. 2, pp. 106-180, 2006.

[10] S. Yan, Y. Fang, and Z. Gao, "Quartz crystal microbalance for the determination of daminozide using molecularly imprinted polymers as recognition element," Biosensors and Bioelectronics, vol. 22, no. 6, pp. 1087-1091, 2007.

[11] L. Ye and K. Mosbach, "Molecular imprinting: synthetic materials as substitutes for biological antibodies and receptors," Chemistry of Materials, vol. 20, no. 3, pp. 859-868, 2008.

[12] E. V. Piletska, A. R. Guerreiro, M. J. Whitcombe, and S. A. Piletsky, "Influence of the polymerization conditions on the performance of molecularly imprinted polymers," Macromolecules, vol. 42, no. 14, pp. 4921-4928, 2009.

[13] A. Poma, A. P. F. Turner, and S. A. Piletsky, "Advances in the manufacture of MIP nanoparticles," Trends in Biotechnology, vol. 28, no. 12, pp. 629-637, 2010.

[14] G. Vasapollo, R. D. Sole, L. Mergola et al., "Molecularly imprinted polymers: present and future prospective," International Journal of Molecular Sciences, vol. 12, no. 9, pp. 5908-5945, 2011.

[15] G. Vlatakis, L. I. Andersson, R. Müller, and K. Mosbach, "Drug assay using antibody mimics made by molecular imprinting," Nature, vol. 361, no. 6413, pp. 645-647, 1993.

[16] Q.-Z. Feng, L.-X. Zhao, B.-L. Chu, W. Yan, and J.-M. Lin, "Synthesis and binding site characteristics of 2,4,6-trichlorophenolimprinted polymers," Analytical and Bioanalytical Chemistry, vol. 392, no. 7-8, pp. 1419-1429, 2008.

[17] N. A. Yusof, A. Beyan, J. Haron, and N. A. Ibrahim, "Synthesis and characterization of a molecularly imprinted polymer for $\mathrm{Pb}^{2+}$ uptake using 2-vinylpyridine as the complexing monomer," Sains Malaysiana, vol. 39, no. 5, pp. 829-835, 2010.

[18] S. S. Milojković, D. Kostoski, J. J. Čomor, and J. M. Nedeljković, "Radiation induced synthesis of molecularly imprinted polymers," Polymer, vol. 38, no. 11, pp. 2853-2855, 1997.

[19] M. C. Blanco-López, M. J. Lobo-Castañón, A. J. MirandaOrdieres, and P. Tuñón-Blanco, "Voltammetric sensor for vanillylmandelic acid based on molecularly imprinted polymermodified electrodes," Biosensors and Bioelectronics, vol. 18, no. 4, pp. 353-362, 2003.

[20] L. Zhang, G. Cheng, and C. Fu, "Synthesis and characteristics of tyrosine imprinted beads via suspension polymerization," Reactive and Functional Polymers, vol. 56, no. 3, pp. 167-173, 2003.

[21] N. Pérez-Moral and A. G. Mayes, "Comparative study of imprinted polymer particles prepared by different polymerisation methods," Analytica Chimica Acta, vol. 504, no. 1, pp. 15-21, 2004.

[22] M. Andaç, S. Mirel, S. Şenel, R. Say, A. Ersöz, and A. Denizli, "Ion-imprinted beads for molecular recognition based mercury removal from human serum," International Journal of Biological Macromolecules, vol. 40, no. 2, pp. 159-166, 2007.

[23] T. Zhou, L. Jørgensen, M. A. Mattebjerg, I. S. Chronakis, and L. Ye, "Molecularly imprinted polymer beads for nicotine recognition prepared by RAFT precipitation polymerization: a step forward towards multi-functionalities," RSC Advances, vol. 4, no. 57, pp. 30292-30299, 2014.

[24] S. Boonpangrak, M. J. Whitcombe, V. Prachayasittikul, K. Mosbach, and L. Ye, "Preparation of molecularly imprinted polymers using nitroxide-mediated living radical polymerization," Biosensors and Bioelectronics, vol. 22, no. 3, pp. 349-354, 2006.

[25] G. Pan, Y. Zhang, X. Guo, C. Li, and H. Zhang, "An efficient approach to obtaining water-compatible and stimuli-responsive molecularly imprinted polymers by the facile surface-grafting of functional polymer brushes via RAFT polymerization," Biosensors and Bioelectronics, vol. 26, no. 3, pp. 976-982, 2010. 
[26] C. Gonzato, M. Courty, P. Pasetto, and K. Haupt, "Magnetic molecularly imprinted polymer nanocomposites via surfaceinitiated RAFT polymerization," Advanced Functional Materials, vol. 21, no. 20, pp. 3947-3953, 2011.

[27] G. Pan, Y. Zhang, Y. Ma, C. X. Li, and H. Q. Zhang, "Efficient one-pot synthesis of water-compatible molecularly imprinted polymer microspheres by facile RAFT precipitation polymerization," Angewandte Chemie International Edition, vol. 50, no. 49, pp. 11731-11734, 2011.

[28] H. Yan and K. H. Row, "Characteristic and synthetic approach of molecularly imprinted polymer," International Journal of Molecular Sciences, vol. 7, no. 5-6, pp. 155-178, 2006.

[29] J.-P. Lai, M.-L. Yang, R. Niessner, and D. Knopp, "Molecularly imprinted microspheres and nanospheres for di(2-ethylhexyl) phthalate prepared by precipitation polymerization," Analytical and Bioanalytical Chemistry, vol. 389, no. 2, pp. 405-412, 2007.

[30] S. T. Wei, A. Molinelli, and B. Mizaikoff, "Molecularly imprinted micro and nanospheres for the selective recognition of $17 \beta$ estradiol," Biosensors and Bioelectronics, vol. 21, no. 10, pp. 19431951, 2006.

[31] D. Vaihinger, K. Landfester, I. Kräuter, H. Brunner, and G. E. M. Tovar, "Molecularly imprinted polymer nanospheres as synthetic affinity receptors obtained by miniemulsion polymerisation," Macromolecular Chemistry and Physics, vol. 203, no. 13, pp. 1965-1973, 2002.

[32] L. I. Andersson and K. Mosbach, "Enantiomeric resolution on molecularly imprinted polymers prepared with only noncovalent and non-ionic interactions," Journal of Chromatography A, vol. 516, no. 2, pp. 313-322, 1990.

[33] O. Ramström and K. Mosbach, "Synthesis and catalysis by molecularly imprinted materials," Current Opinion in Chemical Biology, vol. 3, no. 6, pp. 759-764, 1999.

[34] K. Yano and I. Karube, "Molecularly imprinted polymers for biosensor applications," TrAC-Trends in Analytical Chemistry, vol. 18, no. 3, pp. 199-204, 1999.

[35] E. Caro, R. M. Marce, F. Borrull, P. A. G. Cormack, and D. C. Sherrington, "Application of molecularly imprinted polymers for the analysis of pesticide residues in Food: a highly selective and innovative approach," Trends in Analytical Chemistry, vol. 25, no. 2, pp. 143-154, 2006.

[36] J.-P. Lai, X.-Y. Lu, C.-Y. Lu, H.-F. Ju, and X.-W. He, "Preparation and evaluation of molecularly imprinted polymeric microspheres by aqueous suspension polymerization for use as a high-performance liquid chromatography stationary phase," Analytica Chimica Acta, vol. 442, no. 1, pp. 105-111, 2001.

[37] J.-P. Lai, X.-F. Cao, X.-L. Wang, and X.-W. He, "Chromatographic characterization of molecularly imprinted microspheres for the separation and determination of trimethoprim in aqueous buffers," Analytical and Bioanalytical Chemistry, vol. 372, no. 2, pp. 391-396, 2002.

[38] E. Turiel, J. L. Tadeo, P. A. G. Cormack, and A. Martin-Esteban, "HPLC imprinted-stationary phase prepared by precipitation polymerisation for the determination of thiabendazole in fruit," Analyst, vol. 130, no. 12, pp. 1601-1607, 2005.

[39] J. Wang, P. A. G. Cormack, D. C. Sherrington, and E. Khoshdel, "Monodisperse, molecularly imprinted polymer microspheres prepared by precipitation polymerization for affinity separation applications," Angewandte Chemie International Edition, vol. 42, no. 43, pp. 5336-5338, 2003.

[40] D. A. Spivak, "Optimization, evaluation, and characterization of molecularly imprinted polymers," Advanced Drug Delivery Reviews, vol. 57, no. 12, pp. 1779-1794, 2005.
[41] N. Arabzadeh and M. Abdouss, "Synthesis and characterization of molecularly imprinted polymers for selective solid-phase extraction of pseudoephedrine," Colloid Journal, vol. 72, no. 4, pp. 446-455, 2010.

[42] F. Bai, X. Yang, R. Li, B. Huang, and W. Huang, "Monodisperse hydrophilic polymer microspheres having carboxylic acid groups prepared by distillation precipitation polymerization," Polymer, vol. 47, no. 16, pp. 5775-5784, 2006.

[43] M. Okubo and T. Nakagawa, "Formation of multihollow structures in crosslinked composite polymer particles," Colloid and Polymer Science, vol. 272, no. 5, pp. 530-535, 1994.

[44] M. R. Ferrick, J. Murtagh, and J. K. Thomas, "Synthesis and characterization of polystyrene latex particles," Macromolecules, vol. 22, no. 4, pp. 1515-1517, 1989.

[45] A. J. Paine, W. Luymes, and J. McNulty, "Dispersion polymerization of styrene in polar solvents. 6. Influence of reaction parameters on particle size and molecular weight in $\operatorname{poly}(\mathrm{N}$ vinylpyrrolidone)-stabilized reactions," Macromolecules, vol. 23, no. 12, pp. 3104-3109, 1990.

[46] K. Li and H. D. H. Stöver, "Synthesis of monodisperse poly(divinylbenzene) microspheres," Journal of Polymer Science, Part A: Polymer Chemistry, vol. 31, no. 13, pp. 3257-3263, 1993.

[47] T. J. Romack, E. E. Maury, and J. M. DeSimone, "Precipitation polymerization of acrylic acid in supercritical carbon dioxide," Macromolecules, vol. 28, no. 4, pp. 912-915, 1995.

[48] S. Sosnowski, M. Gadzinowski, and S. Slomkowski, "Poly(L,Llactide) microspheres by ring-opening polymerization," Macromolecules, vol. 29, no. 13, pp. 4556-4564, 1996.

[49] F. Bai, X. L. Yang, Y. Z. Zhao, and W. Q. Huang, "Synthesis of narrow or monodisperse poly(divinylbenzene) microspheres by distillation-precipitation polymerization," Polymer International, vol. 54, no. 26, pp. 168-174, 2004.

[50] F. G. Tamayo, J. L. Casillas, and A. Martin-Esteban, "Evaluation of new selective molecularly imprinted polymers prepared by precipitation polymerisation for the extraction of phenylurea herbicides," Journal of Chromatography A, vol. 1069, no. 2, pp. 173-181, 2005.

[51] J. Park, H. A. Dam, and D. Kim, "Selective sorption behavior of metal(II) ion-imprinted polymethacrylate microspheres synthesized via precipitation polymerization method," Korean Journal of Chemical Engineering, vol. 32, no. 5, pp. 967-973, 2015. 

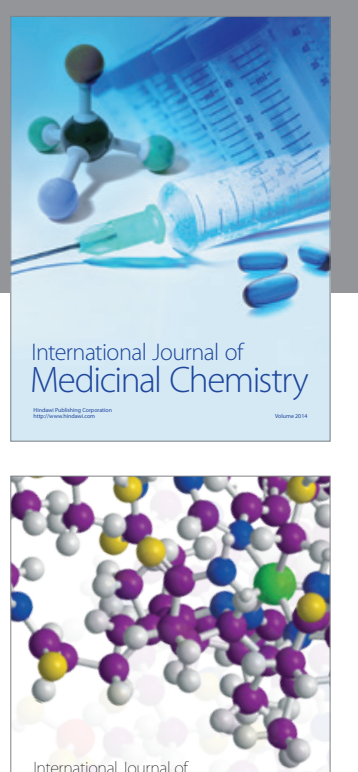

Carbohydrate Chemistry

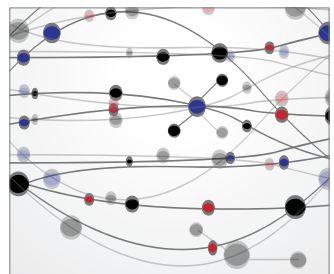

The Scientific World Journal
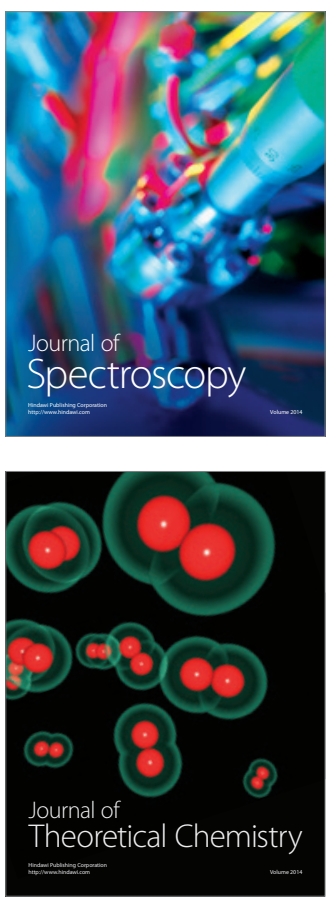
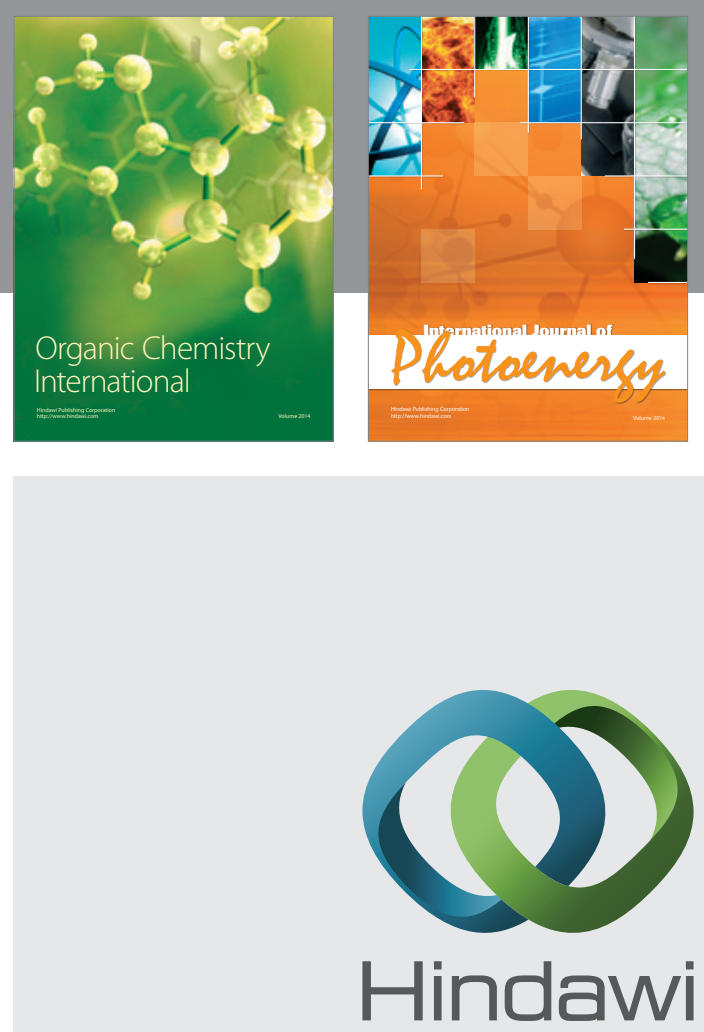

Submit your manuscripts at

http://www.hindawi.com

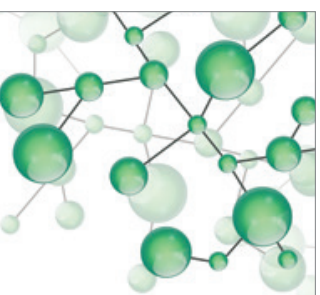

International Journal of

Inorganic Chemistry

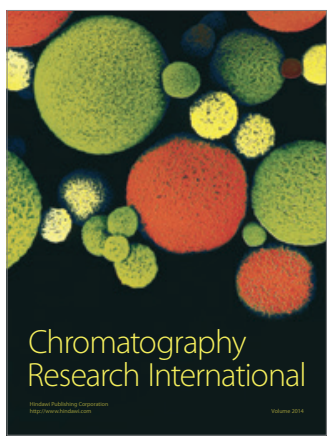

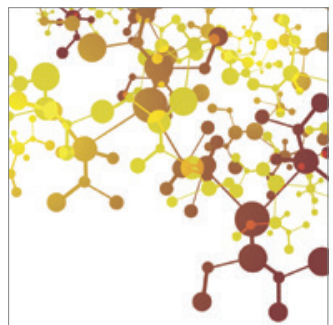

Applied Chemistry
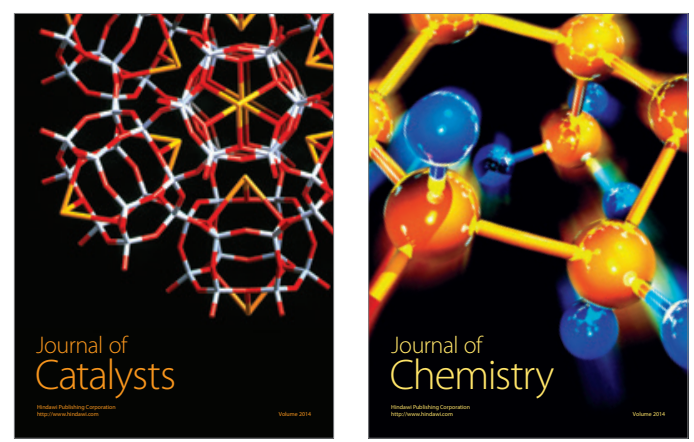
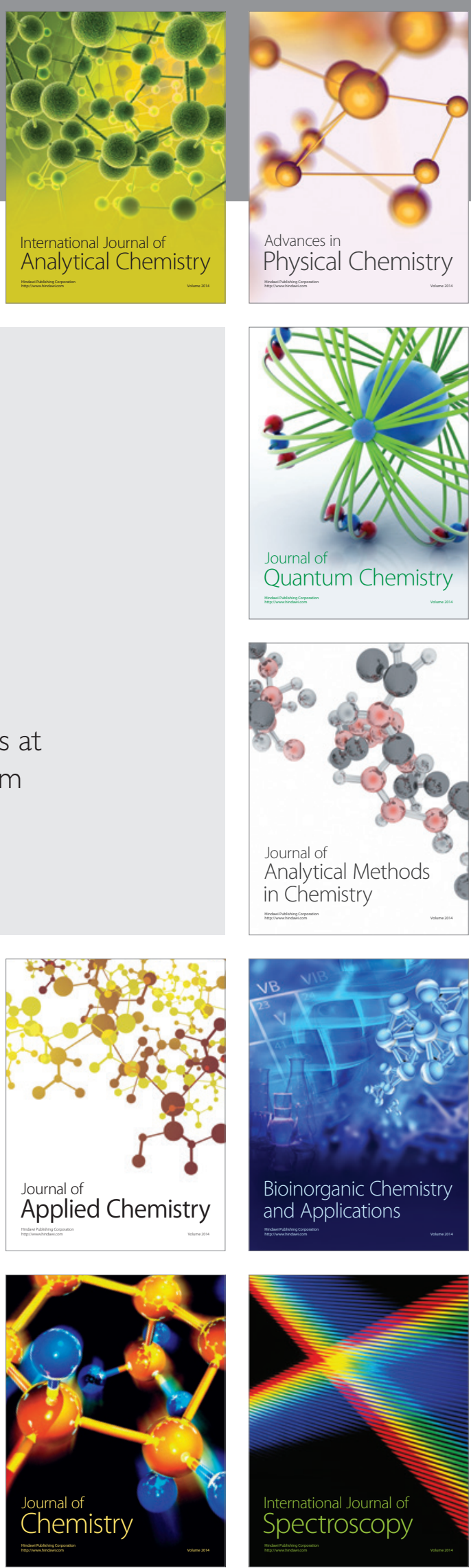